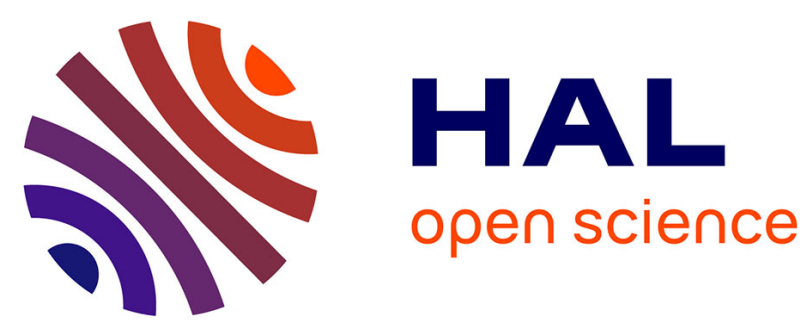

\title{
Effect of Mechanical Loading on Osteogenesis of Human Embryonic Stem Cell-Derived Mesenchymal Progenitors within Collagen Microspheres
}

\author{
Shariatzadeh M, Adrien Baldit, C. M Perreault, David Lacroix
}

\section{- To cite this version:}

Shariatzadeh M, Adrien Baldit, C. M Perreault, David Lacroix. Effect of Mechanical Loading on Osteogenesis of Human Embryonic Stem Cell-Derived Mesenchymal Progenitors within Collagen Microspheres. Journal of Cell Science \& Therapy, 2018, 09 (03), 10.4172/2157-7013.1000282 . hal02063137

\section{HAL Id: hal-02063137 \\ https://hal.univ-lorraine.fr/hal-02063137}

Submitted on 10 Mar 2019

HAL is a multi-disciplinary open access archive for the deposit and dissemination of scientific research documents, whether they are published or not. The documents may come from teaching and research institutions in France or abroad, or from public or private research centers.
L'archive ouverte pluridisciplinaire HAL, est destinée au dépôt et à la diffusion de documents scientifiques de niveau recherche, publiés ou non, émanant des établissements d'enseignement et de recherche français ou étrangers, des laboratoires publics ou privés. 


\title{
Effect of Mechanical Loading on Osteogenesis of Human Embryonic Stem Cell-Derived Mesenchymal Progenitors within Collagen Microspheres
} Shariatzadeh $\mathbf{M}^{1 *}$, Baldit $\mathrm{A}^{1,2}$, Perrault $\mathrm{CM}^{1}$ and Lacroix $\mathrm{D}^{1}$

${ }^{1}$ INSIGNEO-Institute for In-silico Medicine, Department of Mechanical Engineering, University of Sheffield, UK ${ }^{2}$ Université Lorraine - ENIM, CNRS, Arts et Métiers Paris Tech, LEM3, F-57000 Metz, France

\begin{abstract}
Mechanical forces and 3D topological environment can be used to control differentiation of mesenchymal stem cells. However, mesenchymal stem cell fate determined by the effect of physical and mechanical cues is not yet fully understood. Understanding how mechanical cues in the microenvironment orchestrate stem cell differentiation provides valuable insight that can be used to improve current techniques in cell therapy. This study investigates the osteogenic effect of mechanical stimulations on soft cellular microspheres loaded with human embryonic stem cellderived mesenchymal progenitors (hES-MPs) when subjected to dynamic loading and in the absence of chemical stimulation. Microspheres were produced by gelation of bovine collagen type I with 1000 to 2000 hES-MP cells seeded per droplet. Four loading conditions were studied: (1) 10\% constant strain was applied by a Bose biodynamic bioreactor for $15 \mathrm{~min} /$ day or $40 \mathrm{~min} /$ day for 5 or 10 days respectively; (2) $10 \%$ adjusted strain was applied (subtraction of polydimethylsiloxane (PDMS) plastic elongation from global strain) using Bose biodynamic bioreactor for the same 4 duration/conditions as in the constant strain protocol. The results indicate that applying mechanical stimulation to hES-MPs/collagen microspheres induced osteogenic differentiation of cells when the loading protocol was adjusted Alkaline phosphatase activity of samples in the adjusted loading protocol increased significantly on day 14 whilst, the deposited minerals, matrix reorganisation and alignment of collagen fibres enhanced from day 21 post encapsulation onward. Application of cyclic loading to 3D culture of hES-MP cells can be used as a model to regulate mechanostimulation and linage differentiation in vitro.
\end{abstract}

Keywords: Stem cell; Osteogenic differentiation; Mechanical stimulation; Collagen microspheres; Regenerative medicine

\section{Introduction}

Many cell types including osteoblasts, chondrocytes, fibroblasts and endothelial cells are load sensitive and are subjected to daily mechanical loading in vivo. Dense connective tissues like tendon and ligament are stretched frequently through muscle contraction caused by movement whereas bone is under dynamic loading to resist and adapt to the experienced forces by maintaining homoeostasis through tissue remodelling. Most of the forces applied in vivo are dynamic and cyclic which means often the tissue is under loading and resting cycles. For example, femur and tibia undergo cyclic compression and tensile forces during locomotion. Therefore, it is possible that cells respond more to cyclic loading as opposed to constant loading. Constant loading may increase the risk of the cells being overloaded and becoming unresponsive to the applied load [1-3]. A key area of research in tissue engineering is concerned with finding the answers to how mechanical loading transfers to the cells, how cells sense mechanical forces and how and when cells respond to the applied external stimuli. Both 2D and $3 \mathrm{D}$ cultures have been used to apply mechanical loading onto cells [2], although 2D experiments such as gelatine coated plastic and glass are somewhat limited since they do not accurately mimic the complex 3D in vivo architecture. Therefore, these surfaces do not fulfil the necessary requirements for culture and regeneration of functional tissues. Thus, 3D in vitro models may provide more physiologically relevant environments for mechanotransduction studies [4].

Studies have shown that cell response in $2 \mathrm{D}$ cultures in response to dynamic stimulation is predominantly due to the deformation of the substrate with additional minor fluid flow effects, since the minimal movement of fluid flow has subsequent minimal effect on the cell [57]. In contrast, cell response to load in $3 \mathrm{D}$ environments is related to both the mechanical stimulation initiated within the system and the nutrient transport mechanism generated by fluid movement through the scaffold [8]. Culturing cells on/in 3D environments provides a more realistic and physiologically-relevant model for studying load driven biochemical responses in cells since they more closely mimic in vivo conditions [9].

Many studies have investigated the role of mechanical stimulation in controlling cell fate, including mechanical conditioning of mesenchymal stem cells (MSCs) to direct MSC behaviour and differentiation for tissue engineering applications. Delaine-Smith et al. reported that tensile loading favours osteogenic cell differentiation through initiation of a more fibrous matrix whilst, compression loading encourages generation of a glycosaminoglycan (GAG) rich matrix which facilitates chondrogenesis [10]. Other studies have demonstrated the effect of longitudinal forces in up-regulating early alkaline phosphatase (ALP) activity levels and mineralisation markers both in the presence and absence of osteogenic media [11,12]. To date there are limited studies on the effect of cyclic loading on the osteogenesis of stem cells.

The aim of this study was to investigate the effects of cyclic mechanical-induced osteogenic differentiation and long-term proliferation of progenitor cells and assess the cellular mechanisms involved in the mechanotransduction and osteogenesis of embryonic

*Corresponding author: Shariatzadeh M, INSIGNEO Institute for In-silico Medicine, Department of Mechanical Engineering, University of Sheffield, UK, Tel: +44 (0)1509564826; E-mail: m.m.shariatzadeh@lboro.ac.uk

Received: May 21, 2018; Accepted: June 11, 2018; Published: June 18, 2018

Citation: Shariatzadeh M, Baldit A, Perrault CM, Lacroix D (2018) Effect of Mechanical Loading on Osteogenesis of Human Embryonic Stem Cell-Derived Mesenchymal Progenitors within Collagen Microspheres. J Cell Sci Ther 9: 282. doi: $10.4172 / 2157-7013.1000282$

Copyright: () 2018 Shariatzadeh M, et al. This is an open-access article distributed under the terms of the Creative Commons Attribution License, which permits unrestricted use, distribution, and reproduction in any medium, provided the original author and source are credited. 
Citation: Shariatzadeh M, Baldit A, Perrault CM, Lacroix D (2018) Effect of Mechanical Loading on Osteogenesis of Human Embryonic Stem CellDerived Mesenchymal Progenitors within Collagen Microspheres. J Cell Sci Ther 9: 282. doi: 10.4172/2157-7013.1000282

stem cell-derived mesenchymal progenitors (hES-MPs). The main purpose was to design a polydimethylsiloxane (PDMS)-made loading chamber and develop a loading protocol to apply short bouts of mechanical loading, predominantly tensile and compression, on hESMPs seeded collagen microspheres. Another goal was to investigate the effect of mechanical stimulation on osteogenic differentiation of cells through quantification of ALP activity and deposited minerals levels in hES-MPs seeded collagen microspheres. In addition, cellular matrix production and remodelling along with alignment of collagen fibres were evaluated to confirm load driven differentiation of cells. A previously established applied loading regime $[10,13]$ was used to subject cells to both indirect dynamic compression and tensile forces through a PDMS loading chamber.

\section{Material and Methods}

All reagents are from Sigma-Aldrich UK unless otherwise stated.

\section{hES-MPs culture conditions}

A hES-MP cell line (Cellartis, Sweden) were cultured on $0.1 \%$ (wt/ vol) porcine gelatine type A (Sigma, UK) coated surfaces. Expansion and proliferation medium contained $4 \mathrm{~nm}$ fibroblast growth factorbasic recombinant human (FGF- $\beta$ ) (Life technologies, USA; as recommended by manufacturer) added to aMEM (Lonza, UK), 10\% (vol/vol) fetal bovine serum (FBS, Life technologies, UK), 1\% (vol/vol) penicillin and streptomycin (Sigma, UK) and $1 \%$ (vol/vol) L-glutamine (Sigma, UK). Cells were incubated at $37^{\circ} \mathrm{C}$ in $5 \% \mathrm{CO}_{2}$. The medium $(12$ $\mathrm{ml}$ ) was replenished every 2 days.

\section{Collagen gelation procedure and cell seeding}

Bovine collagen type I $(5 \mathrm{mg} / \mathrm{ml})$ solution in $0.02 \mathrm{~N}$ acetic acid (BD Biosciences, UK) was gelated following the manufacturers protocol. Briefly, collagen I was neutralized using $1 \mathrm{~N} \mathrm{NaOH}$ and $10 X$ phosphate buffered saline (PBS, Sigma, UK) and diluted to final concentrations of $2 \mathrm{mg} / \mathrm{ml}$ and $3 \mathrm{mg} / \mathrm{ml}$ on ice. The cells were suspended throughout the collagen solution at a density of $5 \times 10^{5}$ cells $/ \mathrm{ml}$. The volume of each substance and the number of cells required per drop was calculated according to the manufacturer's protocol (BD Biosciences, UK). Collagen microspheres of 2 and $5 \mu$ were dispensed in a $90 \mathrm{~mm}$ diameter Petri dish covered with UV-irradiated parafilm and were incubated for $45 \mathrm{~min}$ at $37^{\circ} \mathrm{C}$ and $5 \% \mathrm{CO}_{2}$ to induce gelation. Gelated collagen/hES-MPs microspheres were then gently flushed with medium to remove them from the parafilm and were transferred to a separate Petri dish. Cell-seeded microspheres were maintained free-floating and the medium was replaced with fresh complete media every $48 \mathrm{~h}$.

\section{Design of a polydimethylsiloxane (PDMS) made loading chamber}

Hypodermic needles (Sigma, UK) with different outer diameter's ranging from $0.6 \mathrm{~mm}$ to $0.9 \mathrm{~mm}$ were used as a template to create a compression chamber. PDMS (PDMS SILGARD ${ }^{\circ} 184$ ) with the ratio of 10:1 of base to initiator was mixed, poured on top of the template and was baked at $60^{\circ} \mathrm{C}$ for $1.5 \mathrm{~h}$. The needle was removed from the set PDMS and the PDMS mould was cut into a rectangular shape (length: $44 \mathrm{~mm}$, width: $28 \mathrm{~mm}$, thickness: $6 \mathrm{~mm}$ ). The same procedure was followed using a $3 \mathrm{ml}$ syringe as a template to make a cylindrical chamber.

\section{Characterisation of PDMS mechanical properties}

Displacement and strain on the PDMS sample surface was calculated using a high resolution digital imaging technique and digital image correlation (DIC) software Kelkins (University of Montpellier) [14]. The Poisson's ratio was obtained computing the transverselongitudinal strain ratio.

\section{Finite element model}

Using Abaqus (Dassault Systèmes, France) a finite element analysis was performed within an elastic framework to estimate the link between the macroscopic load applied on the PDMS and the local loading applied on collagen microspheres. A frictionless surface contact law has been used to manage the relative motion between PDMS and beads bodies

Experimental boundary conditions were applied, i.e., bottom side fixed and top side displaced up to $10 \%$ of strain. Thanks to the geometry of the PDMS chamber only a quarter was simulated taking into account symmetry boundary conditions.

\section{Cyclic loading protocol}

Samples of 10-12 hES-MPs seeded collagen microspheres were transferred to the loading chamber on day 6 post encapsulation (pc). The loading chamber and embedded cell seeded microspheres were subjected to dynamic mechanical stimulation of $10 \%$ strain, $1 \mathrm{~Hz}$ for $15 \mathrm{~min} /$ day to $40 \mathrm{~min} /$ day for 5 and 10 days respectively using ElectroForce 5100 BioDynamic test instrument (ElectroForce System Group, BOSE, USA) and software WinTest 7 as illustrated in Figure 1.

\section{Assessment of collagen fibre alignment}

Alignment of collagen fibres in the control and loaded samples was compared using second harmonic generation (SHG) confocal microscopy (type and brand) on day 21 (pc).

\section{Evaluation of collagen microsphere surface micro structure}

Cell attachment, elongation and new extracellular matrix (ECM) collagen production was examined by scanning electron microscopy (SEM) (Philips XL-20 SEM) on days 6, 16 and $28 \mathrm{pc}$. The microstructure of the collagen beads and the reorganisation of collagen fibres was assessed in the loaded samples versus free floating controls on day $21 \mathrm{pc}$.

\section{DNA count and cell viability}

Cell viability and total DNA measurement of hES-MP cells of free floating control versus loaded samples were determined using fluorescent Quant-iT dsDNA High-Sensitivity Assay Kit (Invitrogen, UK) following the manufacturer's protocol at $24 \mathrm{~h}$, day 6,21 and $28 \mathrm{pc}$. Seeded cells were lysed with a cocktail of cell digestion buffer consisting of: $10 \%$ of cell assay buffer that contained $1.5 \mathrm{~m}$ Tris- $\mathrm{HCl}, 1 \mathrm{~mm} \mathrm{ZnCl}$ and $\mathrm{MgCl}_{2}$ in $\mathrm{ddH}_{2} \mathrm{O}$ mixed with $1 \%$ Triton X-100 and incubated at $4^{\circ} \mathrm{C}$ overnight. Cell lysate samples were then stored at $80^{\circ} \mathrm{C}$ for $10 \mathrm{~min}$ before being incubated at $37^{\circ} \mathrm{C}$ for $45 \mathrm{~min}$ (two freeze thaw cycles) and centrifuged at $10,000 \mathrm{rpm}$ for $5 \mathrm{~min}$. The resulting supernatant was used for DNA quantification. $200 \mu$ of diluted cell lysate reagent (provided in the kit) and $20 \mu \mathrm{l}$ of sample volumes were added to the wells of a 96-well microplate, the fluorescence signal intensity was detected and recorded at $\lambda_{\mathrm{ex}} 485 \mathrm{~nm} ; \lambda_{\mathrm{em}} 520 \mathrm{~nm}$ using Tecan infinite F200 PRO micro plate reader (Labtech, UK).

\section{Measurement of total alkaline phosphatase}

ALP activity of loaded hES-MPs against free floating controls was measured at $24 \mathrm{~h}$, days 6, 14, 21 and $28 \mathrm{pc}$ using an ALP fluorometric assay kit (Abcam, UK). Cells were transferred to a micro centrifuge tube, washed with PBS and lysed with the same lysing cocktail as 
Citation: Shariatzadeh M, Baldit A, Perrault CM, Lacroix D (2018) Effect of Mechanical Loading on Osteogenesis of Human Embryonic Stem CellDerived Mesenchymal Progenitors within Collagen Microspheres. J Cell Sci Ther 9: 282. doi: 10.4172/2157-7013.1000282

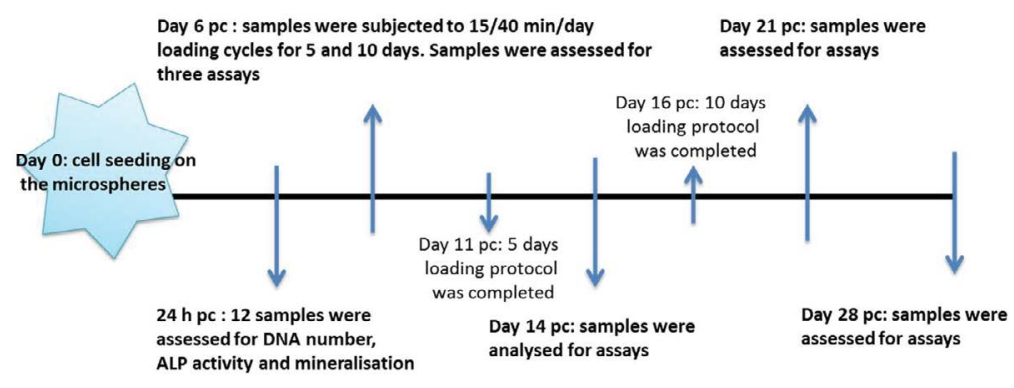

1 (a)

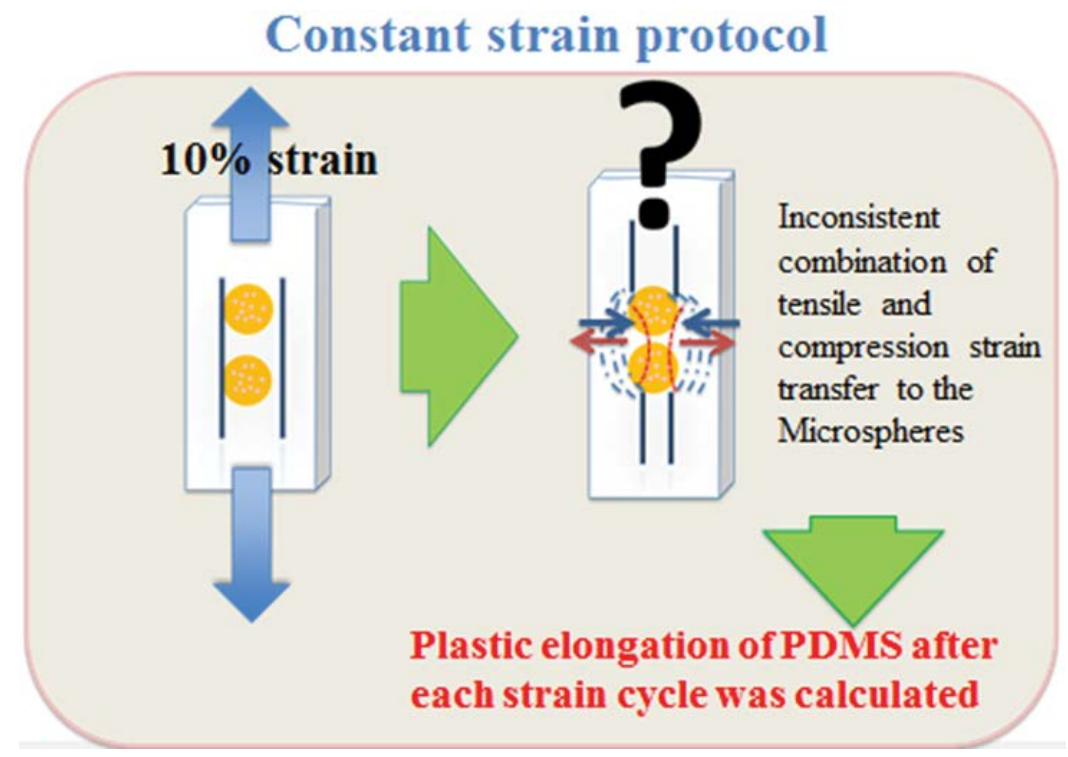

1 (b)

\section{Adjusted strain protocol}

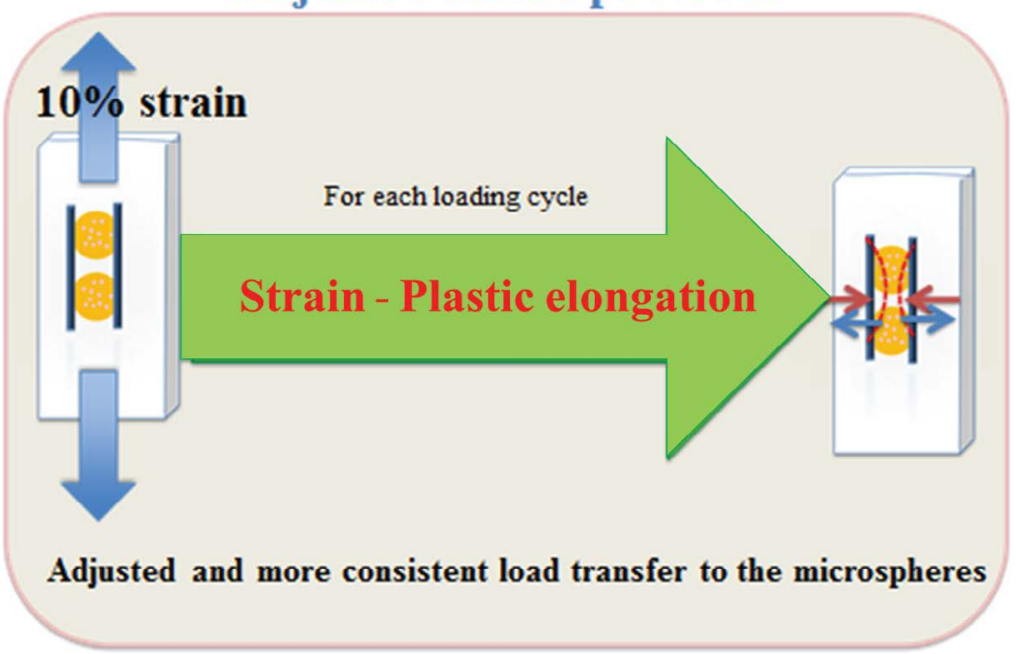

$1(\mathrm{c})$

Figure 1: Schematic diagram of the loading protocols, durations and mechanical conditioning of hES-MPs seeded collagen microspheres within 28 days post en-capsulation. (a): Samples were subjected to either $15 \mathrm{~min} /$ day to $40 \mathrm{~min} /$ day, $10 \% \mathrm{strain}, 1 \mathrm{~Hz}$ for 5 and 10 days. The DNA content, ALP activity level and mineralisation of 12 samples were analysed for each time points. (b): Schematic of the applied constant strain on PDMS made loading chamber which resulted in inconsistent load transfer to the microspheres. (c): Schematic of the applied adjusted strain which shows subtracting the calculated PDMS plastic elongation from global strain may result in more consistent and uniform load transfer to the microspheres. 
previously described for the DNA count. ALP activity was assessed at $\lambda_{\text {ex }} 360 \mathrm{~nm} ; \lambda_{\text {em }} 450 \mathrm{~nm}$ using a fluorescence Nano drop-3300 2.8.0 (Labtech, UK) and normalised to total DNA content.

\section{Quantification of minerals deposition}

Quantification of deposited calcium, phosphorous and zinc was measured by $1 \%$ Alizarin red S staining at 24 h, days $6,14,21$ and 28 pc via Inductively Coupled Emission Spectrometry (ICP-ES), (Perkin Elmer ELAN II DRC) according to the instrument's protocol. Samples were digested in 5\% $(w / v)$ perchloric acid and were diluted 10 times prior to analysis. Samples then were mixed with $1 \%(w / v)$ nitric acid with ratio of 1:1 in Eppendorf tubes. Mineralisation was also visualised on $10 \mu \mathrm{m}$ thick fixed samples using fluorescent microscope, Nikon TiE, (Nikon, UK) by $1 \%$ Alizarin red staining of loaded and control cross section samples over same period of time.

\section{Statistical analysis}

All experiments were performed three times in triplicate $(n=9)$. Cell viability at $24 \mathrm{~h}$, days 6,21 and $28 \mathrm{pc}$, ALP and mineralisation comparison as well as statistical differences between free floating, unloaded controls and loaded samples were completed using one-way ANOVA followed by Sidak's or Tukey's multiple comparisons test using GraphPad Prism 6.

\section{Results}

\section{Design of a PDMS made compression chamber}

A loading chamber was made from PDMS and the central channel diameter was optimised based on the measurement of average collagen microsphere diameter $(\mathrm{n}=20)$ on day $6 \mathrm{pc}$ as shown in Figure 2 . Based on the computational modelling, the chamber's diameter was calculated and made in such a way that it was approximately $50 \mu \mathrm{m}$ $80 \mu \mathrm{m}$ bigger than the diameter of cell seeded collagen beads on day 6 pc [15]. Principal strain on the PDMS chamber was calculated by computational modelling that revealed high stress appeared close to the sample peripheries while local strain was quite constant and close to $10 \%$ equivalent to the macroscopic load at the centre and along half sample height (Figure 3). Also, the computational modelling indicated that maximum of $5 \%$ strain would be transferred to the microspheres inside the loading chamber. This is also consistent with the fact that the chamber needs to be stretched with a $5 \%$ strain to reach the contact with the beads. In addition, the contact sensitivity is related to the geometry of PDMS sample as with the rectangular cross section, it appears that the contact is first reached in the direction corresponding to the shortest geometry length compared with the square sample (Figure 4).

\section{Characterisation of PDMS mechanical properties}

The displacement/strain on the surface of the PDMS was calculated using DIC software Kelkins [14] and an average for the imposed $10 \%$ global strain, $7.5 \%$ strain along the vertical direction of solicitation and $3.75 \%$ strain along the horizontal transverse direction was measured as demonstrated in Figure 5. Poisson's ratio was then calculated as 0.5 as expected from polymer behaviour. Young's modulus of the polymer was calculated as $1000 \mathrm{kPa}$ after relaxation and plastic deformation was calculated as $0.7 \mathrm{~mm}$ after applying $10 \%$ strain and using cycle's blocks on the Bose biodynamic machine.

Comparison of cell proliferation, ALP activity and mineralisation between adjusted and constant loading protocols

DNA pico green assay results showed that cells remained viable and proliferated steadily well over 28 days pc in all conditions as shown in Figure 6. In the constant loading regime, free floating controls had a significantly higher total DNA content than all other experimental groups on days 14, 21 and $28 \mathrm{pc}(\mathrm{p}<0.0001)$. In addition, both 15 and $40 \mathrm{~min} /$ day loaded samples of 10 days regime showed slightly higher cell number than 5 days regime conditions by the end of 28 days experiment, but no statistical significance was observed between the loaded conditions of 5 and 10 days.

The results of ALP level revealed no substantial change in enzyme activity in the loaded samples compared to unloaded and free-floating controls following the application of constant loading over 28 days pc (Figure 6). ALP activity in free floating controls increased to the highest level on day $14 \mathrm{pc}$ and reduced by half on days 21 and $28 \mathrm{pc}(0.00186$, 0.00121 and 0.0011 respectively). However, the enzyme activity did not show any increase on days 14, 21 and $28 \mathrm{pc}$ in the other experimental groups. The 10 day loaded samples for both $15 \mathrm{~min} /$ day and $40 \mathrm{~min}$ /day presented marginally more ALP activity level than 5 day loading regime on day 21 (0.00074, 0.00082, 0.00071 and 0.00058 respectively). Still, free floating controls reported higher enzyme activity level particularly in comparison with 5 day loaded samples of $15 \mathrm{~min} /$ day and $40 \mathrm{~min} /$ day and unloaded controls ( $\mathrm{p}<0.001,0.1$ and 0.0001 respectively) on day $21 \mathrm{pc}$.

ALP activity level in the adjusted loading protocol increased substantially from day 6 to day $14 \mathrm{pc}$ when the activity level reached a peak, followed by a drop to nearly half the level on day 21 , which then remained stable up to day $28 \mathrm{pc}$. On day 14, the ALP level in 5 and 10 days loading regimes of $40 \mathrm{~min} /$ day loaded samples surged significantly up to $40 \%(\mathrm{p}<0.0001)$ compared to both free floating controls and $15 \mathrm{~min} /$ day samples. In addition, all 10 days loading cycles samples showed slightly higher ALP activity levels compared to other conditions on day $28 \mathrm{pc}$, but no statistical significance was found between these experimental groups on day $28 \mathrm{pc}$. Deposited calcium was detected from day 21 and showed significant increase on day 28 pc as shown in Figure 7. Loaded samples in adjusted loading protocol presented the highest calcium level compared to other groups on day $28 \mathrm{pc}$ which was nearly twice as much as detected deposited calcium in free floating $(27,000 \mu \mathrm{g} / \mathrm{l}, \mathrm{p}<0.0001)$. In addition, the calcium level of unloaded 10 days controls on day $28 \mathrm{pc}$ was reported to be around $25 \%$ higher than free floating controls and $75 \%$ greater than its values in loaded samples that were subjected to the constant loading protocol. Loaded samples under the constant loading protocol presented lowest calcium level among other experimental groups from day 21 onward. The calcium quantification results were further confirmed by Alizarin red staining of loaded and control samples cross sections. Both loaded samples under adjusted loading protocol and free-floating controls presented more intense red colour in comparison with 10 days controls on day $28 \mathrm{pc}$ (Figure 8). Phosphorous concentration of adjusted protocol loaded samples increased up to $80 \%$ from day 21 to $28 \mathrm{pc}$ and its concentration was reported 2.5 times higher than that of loaded samples in constant protocol on day $28 \mathrm{pc}(\mathrm{p}<0.01)$ as indicated in Figure 7. Also, free floating controls showed higher phosphorous level compared to unloaded controls and loaded samples of constant protocol (30\%, p $<0.01$ and $67 \%$ respectively) on day $28 \mathrm{pc}$.

Zinc levels of loaded samples in the adjusted protocol was four times higher than its value in free floating controls and nearly 10 times greater than of that in loaded samples of the constant protocol on day $21 \mathrm{pc}$. Zinc concentration of loaded samples in the adjusted protocol declined by $25 \%$ on day $28 \mathrm{pc}$ whereas, all the other groups presented higher level of zinc compared to the earlier time points. 
Citation: Shariatzadeh M, Baldit A, Perrault CM, Lacroix D (2018) Effect of Mechanical Loading on Osteogenesis of Human Embryonic Stem CellDerived Mesenchymal Progenitors within Collagen Microspheres. J Cell Sci Ther 9: 282. doi: 10.4172/2157-7013.1000282

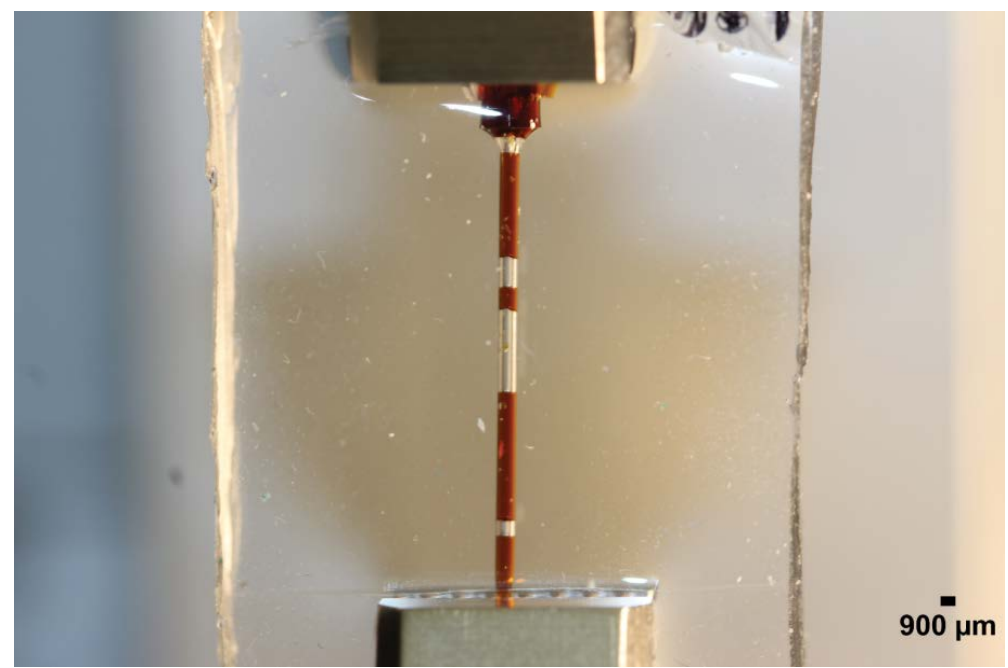

Figure 2: PDMS made compression chamber, ID: $0.9 \mathrm{~mm}$.
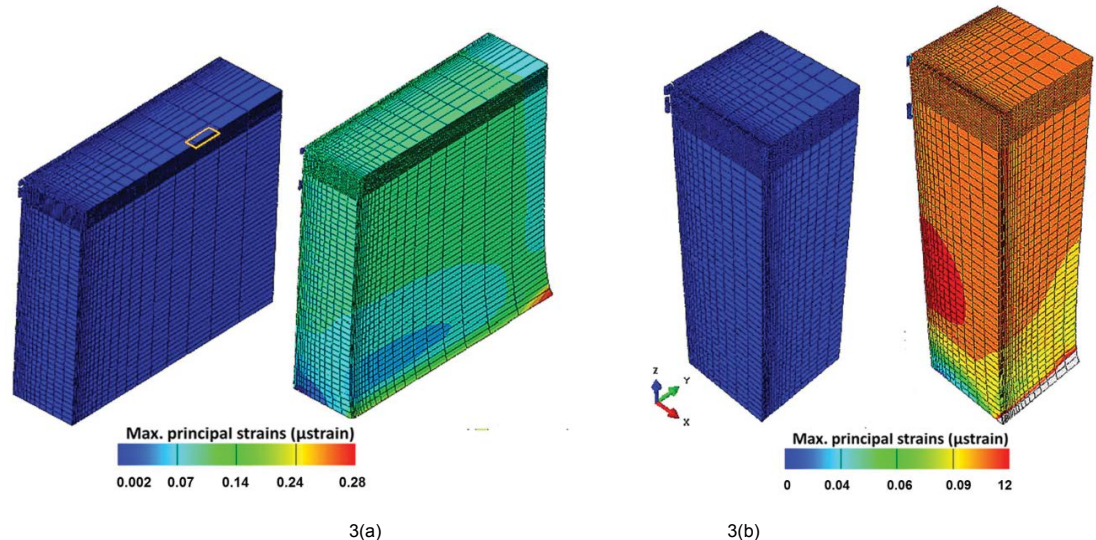

$3($ b)

Figure 3: Beads strain field corresponding to $10 \%$ of strain applied macroscopically on the PDMS sample (Abaqus). (a): Rectangular cross section, (b): Squared cross section. Microspheres inside the loading chamber would sense the maximal strain of around $5 \%$ by applying $5 \%$ tensile strain to the loading chamber to reach the contact with beads. Contact sensitivity is related the to the geometry of PDMS sample as with the rectangular cross section, it appears that the contact is first reached in the direction corresponding to the shortest geometry length compared with the square sample.
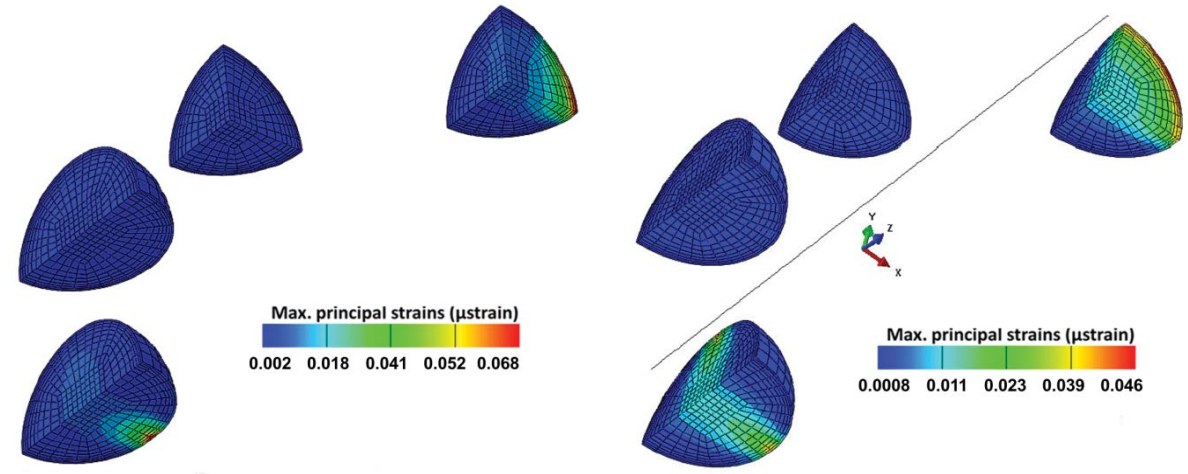

Figure 4: PDMS strain field corresponding to $10 \%$ of strain applied macroscopically (Abaqus). (a): Rectangular cross section. (b): Squared cross section. Strong stress appears close the sample ends but locally in the centre and along half sample height the strain is quite constant and close to $10 \%$ equivalent to the macroscopic load.

\section{Assessment of collagen fibre alignment}

The reorientation and aligned organisation of collagen fibres in loaded samples of adjusted strain protocol was substantially more evident compared to the control free floating samples and unloaded controls which presented more fibrous structure of collagen fibres with no preferential orientation at all depths (Figure 9). The most intense SHG signal was recorded at depth $10 \mu \mathrm{m}$ to $20 \mu \mathrm{m}$ with less coverage area at $20 \mu \mathrm{m}$. The signal was very weak at $30 \mu \mathrm{m}$ which indicated a very 


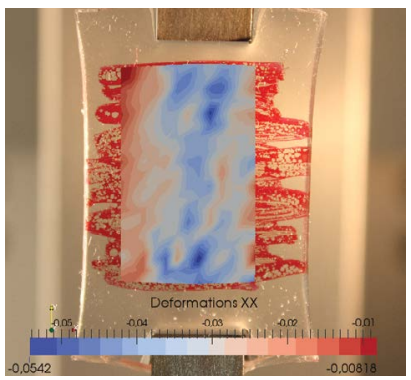

$5(a)$

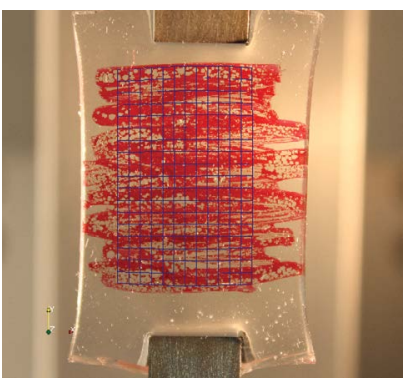

$5(b)$

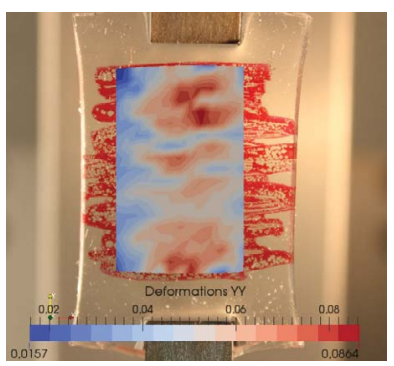

$5(\mathrm{c})$

Figure 5: Measurement of transversal and longitudinal strains on the PDMS surface when subjected to $10 \%$ global strain using Kelkins software. (a): Transverse strain (b): PDMS mesh, and (c): Longitudinal strain.

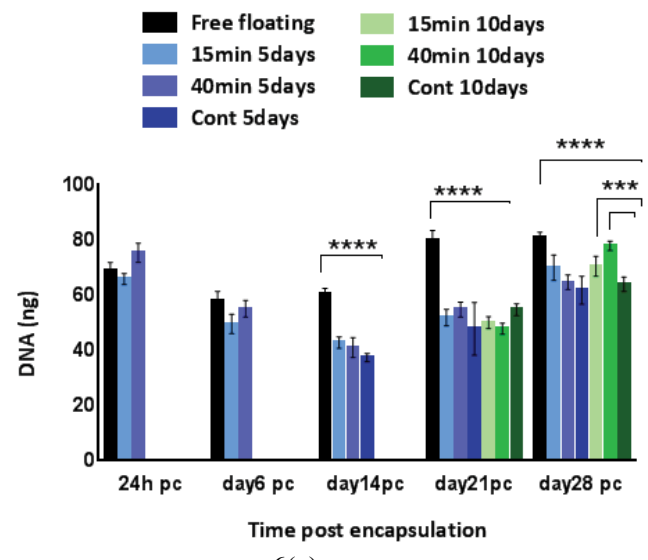

6(a)

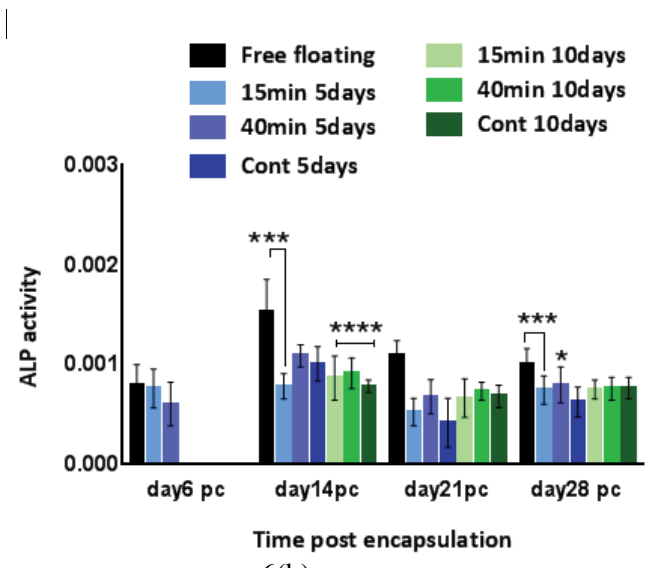

6(b)

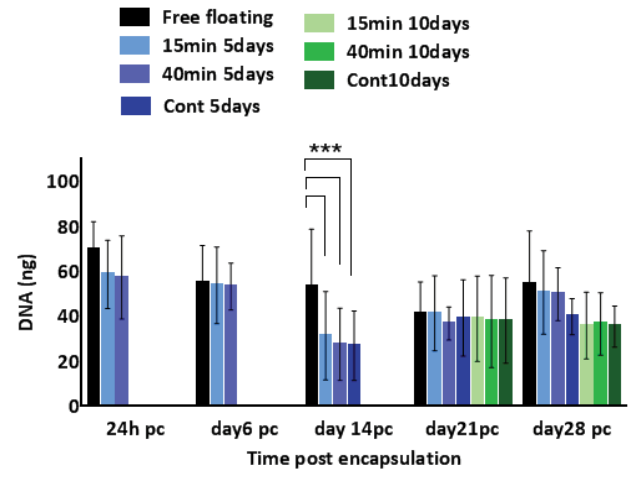

6(c)

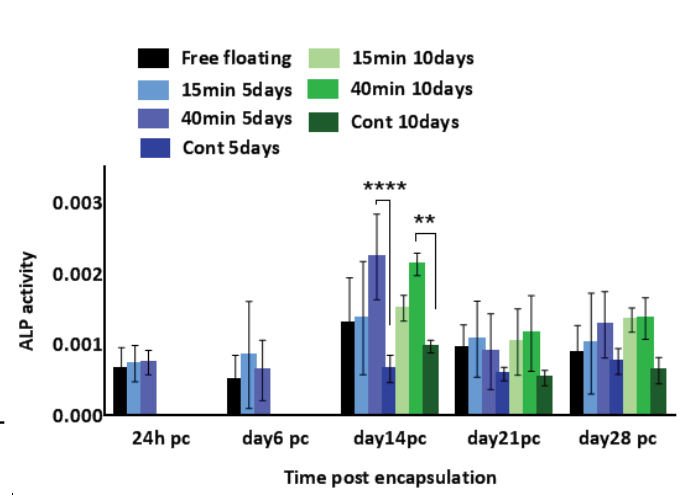

6(d)

Figure 6: Evaluation of cell viability and ALP activity of loaded samples of adjusted loading protocol and constant protocol versus free floating controls. (a) and (c): Total DNA content of loaded samples $15 \mathrm{~min} /$ day and $40 \mathrm{~min} /$ day for 5 and 10 days, compared with controls in the constant and adjusted protocol, (b) and (d): ALP activity of constant and adjusted loading protocols were also compared over 28 days pc. ${ }^{*}$ indicates statistical significance, $\left({ }^{* * * *} p<0.0001 ;{ }^{* * *} p<0.001 ;{ }^{* *} p<0.01 ;{ }^{*} p<0.1\right)$. Data presented as mean \pm SD $n=9$. 
Citation: Shariatzadeh M, Baldit A, Perrault CM, Lacroix D (2018) Effect of Mechanical Loading on Osteogenesis of Human Embryonic Stem CellDerived Mesenchymal Progenitors within Collagen Microspheres. J Cell Sci Ther 9: 282. doi: 10.4172/2157-7013.1000282

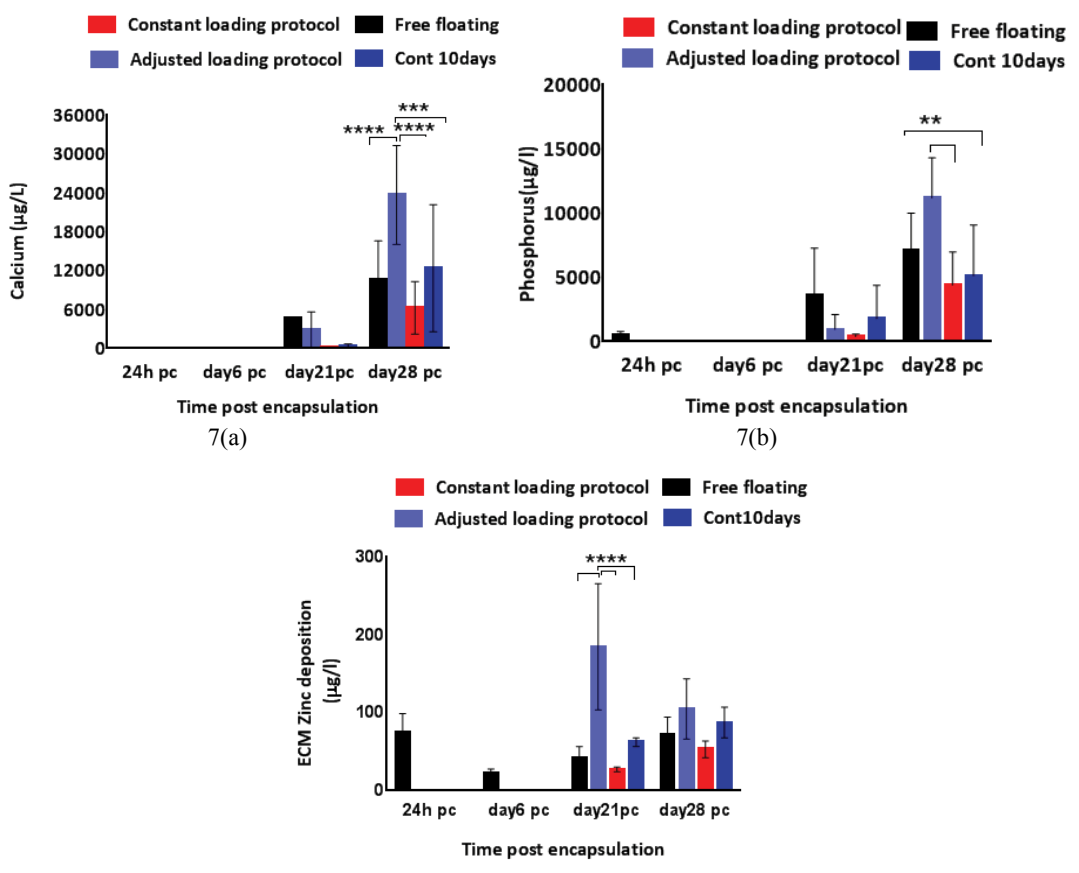

$7(\mathrm{c})$

Figure 7: Evaluation of deposited extracellular matrix calcium, phosphorous and zinc in loaded samples of 40 min/day in 10 days loading regime of constant and adjusted protocols versus controls over 28 days pc. (a): Calcium deposition, (b): Phosphorous deposition, (c): Zinc deposition. "indicates statistical significance, $\left({ }^{* \star *} p<0.0001 ;{ }^{* * *} p<0.001 ;{ }^{* *} p<0.01\right)$. Data is mean \pm SD $n=9$.

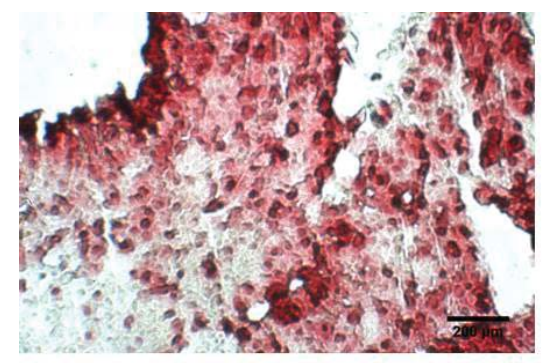

(a) ffc, day $28 \mathrm{pc}$

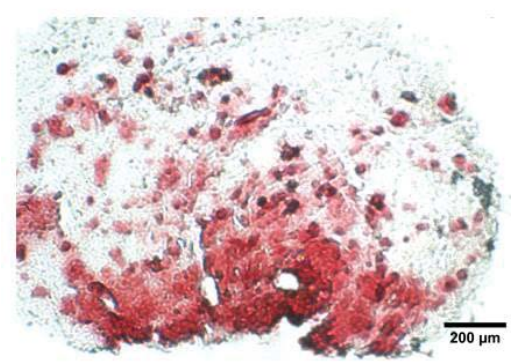

(c) cls 10 days, day $28 \mathrm{pc}$

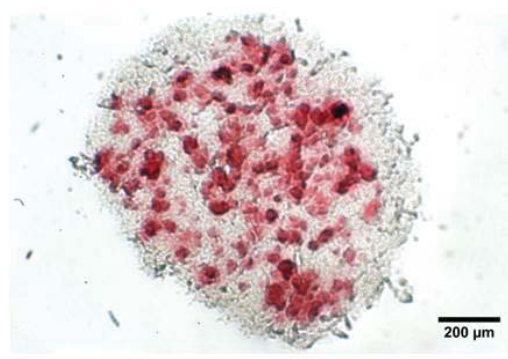

(b) als 10 days, day $28 \mathrm{pc}$

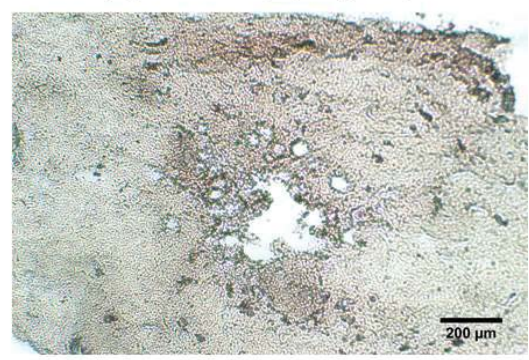

(d) uc 10 days, day $28 \mathrm{pc}$

Figure 8: Alizarin red staining of $10 \mu \mathrm{m}$ thick seeded hES-MPs collagen microspheres on day 28 pc in 10 days cyclic loading regime. ff: Free floating control; cls: Constant loading sample; uc; Unloaded control; als: Adjusted loading sample. All images taken by light microscope, 20x.

low presence of collagen fibres at this point. Evaluation of collagen fibre organisation was assessed using SEM microscopy. The surface structure of collagen microsphere, cellular elongation and ECM reorganisation of collagen fibres were further assessed by SEM microscopy (Figure 10). All cell seeded microspheres were covered with cells and matrix at both time points. Cells and matrix on both time points and conditions did not present any preferential direction of orientation and no cellular or collagen fibre alignment was visible in loaded samples of the adjusted loading protocol versus free floating controls. In addition, deposition of mineral particles was apparent in both loaded samples and freefloating controls on day $28 \mathrm{pc}$ in comparison with day $6 \mathrm{pc}$. Higher accumulation and larger sizes of deposited mineral particles were 
Citation: Shariatzadeh M, Baldit A, Perrault CM, Lacroix D (2018) Effect of Mechanical Loading on Osteogenesis of Human Embryonic Stem CellDerived Mesenchymal Progenitors within Collagen Microspheres. J Cell Sci Ther 9: 282. doi: 10.4172/2157-7013.1000282

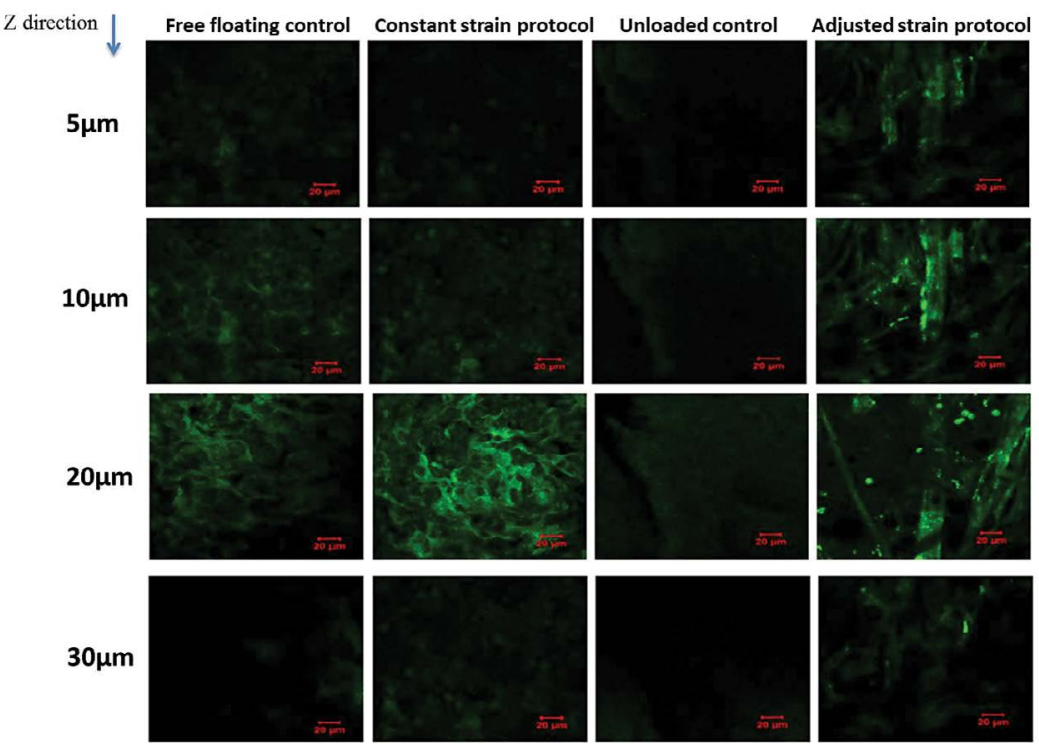

Figure 9: SHG microscopic images of reorientation and alignment of collagen fibres on day 21 pc in 10 days cyclic loading experiment. SHG signal intensity was higher in loaded samples compared to the controls. Ffc; free floating control. Cls; constant loading sample. Uc; unloaded control. Als; adjusted loading sample. Collagen fibres of loaded sample in adjusted protocol visibly reorganised and aligned in comparison with more random organisation of collagen fibre in other conditions. Settings for images taken at $50 \mu \mathrm{m}$ to $75 \mu \mathrm{m}$ from the surface of all samples were optimised to visualise collagen. All images were taken by confocal microscope, EC $40 \mathrm{x} / 1.3$ plan-Neofluar oil DIC.

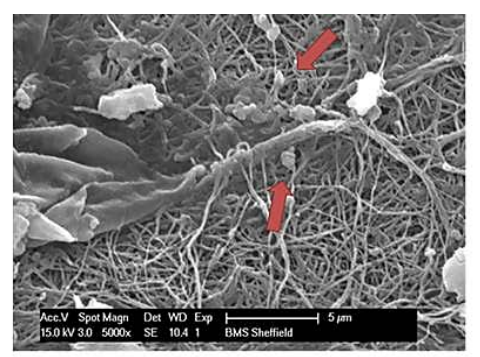

(a) ffc, day $28 \mathrm{pc}$

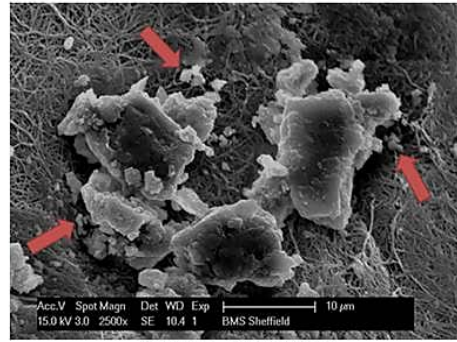

(c) als, day $28 \mathrm{pc}$

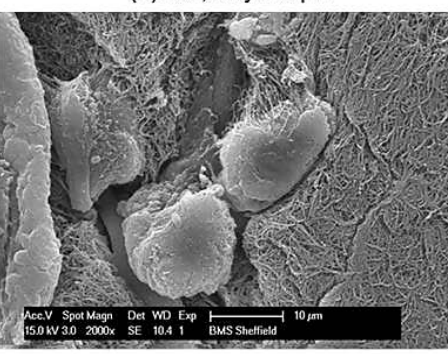

(e) ffc, day $6 \mathrm{pc}$

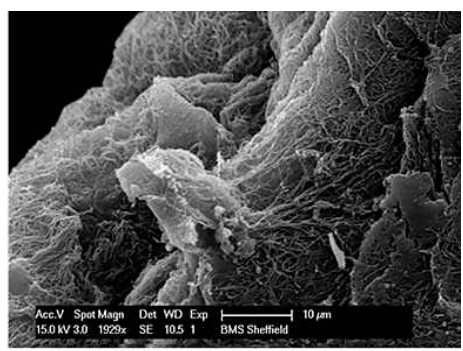

(b) ffc, day $28 \mathrm{pc}$

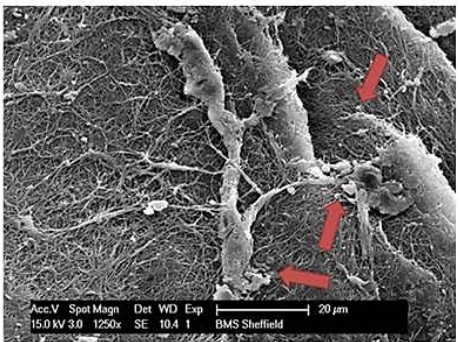

(d) als, day $28 \mathrm{pc}$

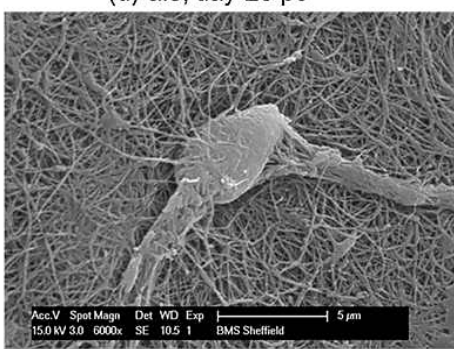

(f) $\mathrm{ffc}$, day $6 \mathrm{pc}$

Figure 10: SEM microscopy of hES-MPs seeded collagen microspheres surface on day 28 pc. FFC: Free floating control; CLS: Constant loading sample; UC; Unloaded control; ALS: Adjusted loading sample. Accumulation of mineral deposits is more evident in both loaded samples and free-floating controls compared to free floating controls on day $6 \mathrm{pc}$. 
visualised in the loaded samples than free floating controls. Collagen fibres of microspheres in both samples and controls were visibly thinner compared to the produced extracellular matrix fibres on day 28 $\mathrm{pc}$ and showed more distinct organisation of fibres as opposed to free floating controls on day $6 \mathrm{pc}$ (Figure 10).

\section{Discussion}

Mechanical stimulation can enhance osteogenic differentiation of hES-MPs seeded collagen microspheres. Our results support other studies that presented that mechanical and physical cues in the stem cell microenvironment controls cell behaviour and promotes osteogenesis of soft 3D progenitor cells by supporting mineral deposition and collagen fibre realignment $[16,17]$.

The adjusted strain regime was superior in stimulating the osteogenesis of hES-MPs compared with the constant strain protocol. The unloaded controls supported up-regulation of ALP activity on day $14 \mathrm{pc}$ by presenting increased calcium and phosphorous deposition on days 21 and $28 \mathrm{pc}[18,19]$. These finding were further confirmed by SHG images of reorganised and reoriented collagen fibres near the periphery of collagen beads, in addition to SEM images of more visible deposited minerals on the surface of collagen microspheres in the adjusted loading samples on day $28 \mathrm{pc}[20,21]$.

Zinc levels have been shown to have a stimulatory effect on mineralization, production of collagen and ALP activity level both in vivo and in vitro [20]. Our results indicated that zinc accumulation was significantly up-regulated in loaded samples of adjusted loading protocol on day $21 \mathrm{pc}$ and declined to half of its value on day $28 \mathrm{pc}$. However, other conditions and controls showed the opposite trend for zinc at the same time points, with higher zinc expression level on day $28 \mathrm{pc}$. Up-regulation of zinc on day $21 \mathrm{pc}$ and prior to increase in the deposited calcium and phosphorous could be explained by an accumulation of zinc in the matrix vesicles that initiates the assembly of hydroxyapatite crystals and mineralisation and was reported on day 28 pc [22]. Higher concentrations of zinc may indicate mineralisation and osteogenic differentiation of hES-MPs through higher MMPs expression level in the ECM, but it also could indicate chondrogenesis of progenitor cells $[23,24]$. Therefore, more studies on the role of zinc in calcification via matrix vesicles and expression levels of osteogenic and chondrogenic MMPs are needed to fully link the up-regulation of zinc with matrix vesicles and expression level of matrix metalloproteinase family members.

Although various studies have shown that tensile and compression loading enhances osteogenesis of primary cells, experimental models still require meticulous planning and design to allow for the transmission of appropriate and effective global strains to the cell local micro environment. Different studies have reported the effect of longitudinal stretching and compression on the osteogenesis and chondrogenic differentiation of stem cells $[25,26]$. Yet, it is still not clear whether compression can induce osteogenesis of stem cells on a soft scaffold [27]. In real physical activity mechanical strain modes are complex and combined mechanical forces act together to influence stem cell fate in the body [28]. Thus, it is more relevant to study the synergistic effect of external mechanical forces on osteogenesis of progenitor cells [29]. Therefore, analysing the combined effects of tensile and compression loading on the cell seeded microspheres was an important focus of this study. The results of the mechanical stimulation of progenitor cells indicated the effectiveness of the adjusted loading protocol in enhancing osteogenesis of the cells, which is in agreement with other studies $[10,11]$. However, there are multiple factors that should be considered for obtaining more significant outcome in future studies [4]. Controlling these factors increase accuracy whilst reducing variability in measuring osteogenic markers and increase the validity of the effect of mechanical loading on osteogenic differentiation of hESMPs in soft 3D cultures [5,6].

One of the most important factors is the geometry of the collagen microspheres that determine the transmission of loads (compression and tensile) through collagen fibres and into the cells. The geometry of collagen beads was assumed spherical and as it was calculated by computational modelling applying $10 \%$ global strain which results in a transfer of around 5\% compression to the centre and more tensile loads to the periphery of the spheres. Due to the nonhomogeneous distribution of the cells in the microspheres and cells tendency to migrate to the surface of collagen beads, in theory, hES-MPS would sense more tensile loads compared to compression. In addition, applying tensile load to the PDMS and compression of the chamber will cause collagen microspheres to be pulled in a longitudinal direction (top to bottom) that would change the geometry of the beads during the experiment. This alteration of bead geometry in opposite direction of being confined and compressed by the PDMS under the loads would also add to the complexity of load transfer. In reality, microsphere geometry varies considerably depending on the number of seeded cells from being close to spherical, oval or three quarter of a sphere that once again increase the variability between samples, experimental conditions and repeats $[29,30]$.

Furthermore, numerical modelling indicated that when a $10 \%$ strain is applied to the construct, the embedded cells receive a different magnitude of strain that decreases exponentially with increasing the distance from the construct surface [31]. These findings were confirmed by Pfeiler's et al. [32] model that evaluated the local loading conditions on hMSCs seeded in 3D collagen scaffold that was exposed to cyclic tensile strain. Their study concluded that global strain applied tensile strain of $10 \%$ resulted in $18.3 \%$ local strain because of geometric variation in the gel shape.

Moreover, osteogenic marker assays were performed on a pool of total extracted cells from the collagen microspheres without considering the local cell number on the specific area (centre or periphery) of the beads and dominance of load type. Therefore, they cannot be a true representative of the effectiveness of the applied mechanical strain on the cells. As a result, cells in different areas of microspheres would sense non-identical load transfer that may lead in inconsistent cellular response and promotion of differentiation. Theses variabilities were confirmed by assessing the histological staining of collagen beads across sections that indicated random accumulation of osteogenic markers stains with no significant preference of the deposited stains intensity in the periphery or centre of the cross sections and between different cross sections of one sample. In addition, the intervaribility between samples caused by very low initial seeded cells and proliferated cells in random areas of beads periphery increased the inconsistency of the results. The intensity of the deposited stain can be affected by very low cell number in specific area of the beads despite assuming that the optimum load transfer condition was carried out.

Better handling of collagen beads is required as hydrogel soft geometry can easily be affected by transferring microspheres to the loading chamber. Due to the very small size and lightweight nature of the microspheres, collagen microspheres may rotate through loading chamber and may cause non-homogeneous transfer of forces to the cells as shown in histological staining of microspheres. Therefore, cells in different areas of a microsphere may experience more random mechanical forces and respond differently to the applied load. 
Citation: Shariatzadeh M, Baldit A, Perrault CM, Lacroix D (2018) Effect of Mechanical Loading on Osteogenesis of Human Embryonic Stem CellDerived Mesenchymal Progenitors within Collagen Microspheres. J Cell Sci Ther 9: 282. doi: 10.4172/2157-7013.1000282

Advanced computational modelling is required to define a more detailed and accurate map of load transfer for specific areas of the collagen microspheres [33]. Such a map would improve our understanding of the transmission of loads and load types to the cells and therefore, would assist in developing an optimum protocol to study the effect of mechanical loading on the cells and cellular response. In addition, conventional in vitro osteogenic marker assays are not sensitive enough for low cell number therefore, even with optimised mechanical conditioning regime quantification and analysis of the changes in osteogenic markers would not be valid. Although applying mechanical stimulation can affect cell commitment, mechanical loading alone may not provide all of the necessary signals for full cell commitment and osteogenesis, thus, combining mechanical and chemical stimulation is critical in osteogenic differentiation of hESMPs as suggested in other studies [34,35].

\section{Conclusion}

This study has demonstrated that mechanical loading can stimulate osteogenic differentiation of $3 \mathrm{D}$ culture of self-assembly hES-MPs seeded collagen microspheres by enhancing both early stage bone markers and mineralisation. Combining computational and experimental studies has provided precise and consistent load transfer into microsphere's fibres and enabled mechanical forces to efficiently be transmitted to the cells. Understanding how mechanical cues in the microenvironment orchestrate stem cell differentiation can provide valuable insight to improve current techniques in cell therapy and organ repair. Hence, the effect of cyclic loading on 3D culture of hES-MP cells could be employed as a model to achieve more in-depth understanding of mechano-stimulation and lineage differentiation both in vitro and in silico. The result of this study can be used as a tool to build more optimised constructs to transfer mechanically stimulated stem cells to the specific area of a defected bone or as cells carriers and implants in bone and cartilage regenerative therapies.

\section{Acknowledgements}

SHG microscopy of samples was carried out by Dr Nicola Green (University of Sheffield) who is gratefully acknowledged. Financial support from the European Research Council (258321) is acknowledged.

\section{Conflict of Interest}

The authors declare that they have no competing interests.

\section{References}

1. Huang C, Hagar KL, Frost LE, Y Sun Y, Cheung HS (2004) Effects of cyclic compressive loading on chondrogenesis of rabbit bone-marrow derived mesenchymal stem cells. Stem Cell 36: 313-323.

2. David V, Martin A, Lafage-Proust MH, Malaval L, Vico L, et al. (2007) Mechanical loading down-regulates peroxisome proliferator-activated receptor gamma in bone marrow stromal cells and favors osteoblastogenesis at the expense of adipogenesis. Endocrinology 148: 2553-2562.

3. Sumanasinghe RD, Bernacki SH, Loboa EG (2006) Osteogenic differentiation of human mesenchymal stem cells in collagen matrices: Effect of uniaxial cyclic tensile strain on bone morphogenetic protein (BMP-2) mRNA expression. Tissue Eng 12: 3459-3465.

4. Barron MJ, Tsai CJ, Donahue SW (2010) Mechanical stimulation mediates gene expression in MC3T3 osteoblastic cells differently in 2D and $3 \mathrm{D}$ environments. J Biomech Eng 132: 41005

5. Juhásová J, Juhás S, Klíma J, Strnádel J, Motlik J, et al. (2011) Osteogenic differentiation of miniature pig mesenchymal stem cells in 2D and 3D environment. Physiol Res 60: 559-571.

6. Yao W, Yi Li Y, Ding G (2012) Interstitial fluid flow: The Mechanical Environment of Cells and Foundation of Meridians. Evidence-Based Complementary and Alternative Medicine 2012: 1-9.
7. Baker BM, Chen CS (2012) Deconstructing the third dimension - how 3D culture microenvironments alter cellular cues. J Cell Sci 125: 3015-3024

8. Tian XF, Heng BC, Ge Z, Lu K, Cao T, et al. (2008) Comparison of osteogenesis of human embryonic stem cells within 2D and 3D culture systems. Scand J Clin Lab Invest 68: 58-67.

9. Arpornmaeklong P, Brown SE, Wang Z, Krebsbach PH (2009) Phenotypic characterization, osteoblastic differentiation, and bone regeneration capacity of human embryonic stem cell-derived mesenchymal stem cells. Stem Cells Dev 18: 955-968.

10. Delaine-smith RM, Reilly GC (2011) The effects of mechanical loading on mesenchymal stem cell differentiation and matrix production. Vitam Horm 87: 417-480.

11. Gurkan UA, Akkus O (2008) The mechanical environment of bone marrow: A review. Ann Biomed Eng 36: 1978-1991.

12. Kearney EM, Farrell E, Prendergast PJ, Campbell VA (2010) Tensile strain as a regulator of mesenchymal stem cell osteogenesis. Ann Biomed Eng 38: $1767-1779$.

13. Mouw JK, Connelly JT, Wilson CG, Michael KE, Levenston ME (2007) Dynamic compression regulates the expression and synthesis of chondrocyte-specific matrix molecules in bone marrow stromal cells. Stem Cell 25: 655-663.

14. Wattrisse B, Chrysochoos A, Muracciole JM, Moz-Gaillard MN (2001) Analysis of strain localization during tensile tests by digital image correlation. Experimental Mechanics 41: 29-39.

15. Olivares AL, Lacroix D (2012) Simulation of cell seeding within a threedimensional porous scaffold: a fluid-particle analysis. Tissue Eng. Part C Methods 18: 624-31.

16. Baldit A and Campos A, Brunelli M, Perrault C, Lacroix D (2014) Multiscale Simulation of Cell Migration for the Guidance of Tissue Growth. VPH Conf 18: 624-631.

17. Hess R, Douglas T, Myers KA, Rentsch B, Rentsch C, et al. (2010) Hydrostatic pressure stimulation of human mesenchymal stem cells seeded on collagenbased artificial extracellular matrices. J Biomech Eng 132: 021001.

18. Sittichokechaiwut A, Edwards JH, Scutt AM, Reilly GC (2010) Short bouts of mechanical loading are as effective as dexamethasone at inducing matrix production by human bone marrow mesenchymal stem cell. Eur Cell Mater 20: 45-57.

19. Friedl G, Schmidt H, Rehak I, Kostner G, Windhager R, et al. (2007) Undifferentiated human mesenchymal stem cells (hMSCs) are highly sensitive to mechanical strain: Transcriptionally controlled early osteochondrogenic response in vitro. Osteoarthr Cartil 15: 1293-1300.

20. Seo HJ, Cho YE, Kim T, Shin HI, Kwun IS (2010) Zinc may increase bone formation through stimulating cell proliferation, alkaline phosphatase activity and collagen synthesis in osteoblastic MC3T3-E1 cells. Nutr Res Pract 4 356-361.

21. Golub EE, Boesze-Battaglia K (1992) The role of alkaline phosphatase in cartilage mineralization. Bone Miner 17: 273-278.

22. Anderson HC (2003) Matrix vesicles and calcification. Curr Rheumatol Rep 5: 222-226.

23. Schneider RK, Puellen A, Kramann R, Raupach K, Neuss S, et al. (2010) The osteogenic differentiation of adult bone marrow and perinatal umbilical mesenchymal stem cells and matrix remodelling in three-dimensional collagen scaffolds. Biomaterial 31: 467-480.

24. Mannello F, Tonti GM, Bagnara GP, Papa S (2006) Role and function of matrix metalloproteinases in the differentiation and biological characterization of mesenchymal stem cells. Stem Cell 24: 475-481.

25. Yang X, Gong P, Lin Y, Zhang L, Li X, et al. (2010) Cyclic tensile stretch modulates osteogenic differentiation of adipose-derived stem cells via the BMP-2 pathway. Arch Med Sci 6: 152-159.

26. Ngiam M, Liao S, Ong Jun Jie T, Xiaodi S, Yixiang D, et al. (2010) Effects of mechanical stimulation in osteogenic differentiation of bone marrow-derived mesenchymal stem cells on aligned nanofibrous scaffolds. Bioact. Compat. Polym 26: 56-70.

27. Mauck RL, Byers BA, Yuan X, Tuan RS (2007) Regulation of cartilaginous ECM gene transcription by chondrocytes and MSCs in 3D culture in response to dynamic loading. Biomech Model Mechanobiol 6: 113-125. 
Citation: Shariatzadeh M, Baldit A, Perrault CM, Lacroix D (2018) Effect of Mechanical Loading on Osteogenesis of Human Embryonic Stem CellDerived Mesenchymal Progenitors within Collagen Microspheres. J Cell Sci Ther 9: 282. doi: 10.4172/2157-7013.1000282

28. Thompson MS, Epari DR, Bieler F, Duda GN (2010) In vitro models for bone mechanobiology: applications in bone regeneration and tissue engineering. Proc Inst Mech Eng Part H J Eng Med 224: 1533-1541.

29. Moraes C, Sun Y, Simmons CA (2011) (Micro) Managing the mechanical microenvironment. Integr Biol. (Camb) 3: 959-971.

30. Pham MH, Buser Z, Acosta FL (2016) Bone Formation in Osteoporosis, In Vitro Mechanical Stimulation as Compared with Biochemical Stimuli. In: Pham P. (ed) Bone and Cartilage Regeneration. Stem Cells in Clinical Applications. Springer, Cham 2016:255-264.

31. Stern AR, Stern MM, Van Dyke ME, Jähn K (2012) Isolation and culture of primary osteocytes from the long bones of skeletally mature and aged mice. BioTechnique 52: 361-373.
32. Pfeiler TW, Sumanasinghe RD, Loboa EG (2008) Finite element modeling of $3 \mathrm{D}$ human mesenchymal stem cell-seeded collagen matrices exposed to tensile strain.J Biomech 41: 2289-2296.

33. Flaibani M, Magrofuoco E, Elvassore N (2010) Computational Modeling of Cell Growth Heterogeneity in a Perfused 3D Scaffold. Ind. Eng Chem Res 49: 859-869.

34. Yourek G, McCormick SM, Mao JJ, Reilly G (2010) Shear stress induces osteogenic differentiation of human mesenchymal stem cells. Regen Med 5: 713-724.

35. Mathews S, Mathew SA, Gupta PK, Bhonde R, Totey S (2014) Glycosaminoglycans enhance osteoblast differentiation of bone marrow derived human mesenchymal stem cells. J Tissue Eng Regen Med 8: 143-152. 